\title{
CONSIDERATIONS REGARDING THE AUDITING OF INFORMATION SYSTEMS
}

\author{
Marius MILANDRU \\ “Nicolae Bălcescu” Land Forces Academy, Sibiu, Romania \\ mnmilandru@yahoo.com
}

\begin{abstract}
At present the approach and application of management within the military organization is marked by the rethinking of managerial positions, scientific breakthroughs and know-how on one hand, and the concern related to the functionality and performance of departments on the other. Such aspects have demonstrated the utmost necessity of an intense and balanced approach to prediction, organization, training, coordination and control-evaluation. In the context of the contemporary globalized business environment, internal auditing has become an essential tool in the leadership of any organization, determining changes and transformations within its constitutive systems (accountancy, decision-making, information, etc.) as well functionality at a high level of performance. The purpose and importance of auditing lies in its stimulation and increase of efficiency within the organization or system it is conducted in, all the more so since it is applied impartially and without compromise, revealing the reality to the leading staff, assuring them that their strategy is correctly applied and that the expected effects in the use of supplies, efficiency and efficacy are the ones predicted.
\end{abstract}

Keywords: military organization, internal auditing, informatic system, objectives, procedures.

\section{Introduction}

Internal auditing as a practice has been strongly influenced by its origins in finance and accounting control, first being implemented in England and France at the beginning of the $60 \mathrm{~s}$.

In Romania, internal public auditing has been adopted as a trendy concept in the field of finance control, yet in the meantime, a separation of the concepts of internal control and internal auditing has been accomplished.

Internal auditing is applied to all organizations regardless of their size or nature, through the extension from the largest organizations to those of mid- or small size, covering all functions within the organization.

Internal auditing, from this viewpoint, functions as a reasonable safety measure assuring that the undertaken operations and the decisions made are under control and that it contributes to the successful task fulfillment within the organization. Otherwise, auditing has to offer recommendations in view of a remedy.

At present, there is a problem in understanding the internal control system, itself subjected to internal auditing, which includes all internal control activities carried out within an entity and the risks associated to them.

\section{The Necessity of Auditing Information Systems}

With the integration of new information technology into the data 
processing, transmission, and storage process, a new series of threats and vulnerabilities of the information system have appeared.

The amplitude and the ramifications of nowadays informatics are leading to the necessity of analysis and evaluation of this system.

The means of the information system that have to be controlled and evaluated are the following: computers, information software (operation systems, informational applications related to economics, database management systems), communication networks, procedures and operations, the policies within the system.

In information system auditing the following criteria will be followed:

- available resources, evaluated in terms of efficient, expedient and economical use, referring to equipment (processors and peripherals) and associated operation resources. For an efficient evaluation, the responsibility for acquisition and management should be clearly separated.

- the auditor's activity will be focused on the performance control over the use of information resources and the implications it has over the management of the entity.

Therefore, the auditor doesn't have to be a specialist in informatics, even though, his familiarity with the terminology and a certain amount of background knowledge is necessary. It should also be mentioned that throughout the evaluation some important aspects may need a thorough analysis by a specialist. Throughout his assessment, the auditor's attention will be focused on analyzing if the necessary informational input is used in order to cover the management of the entity and if it is achieved in a cost-efficient way. Regarding the type of analysis and evaluation, the activities related to the information system are divided into:

performance;
- activities of operation.

The activities of planning and performance are developed in a process that includes:

- a general study of the field in which informatics is applied within the entity, through which a plan of information development is elaborated, known as plan of systems or robotism that contains the applications that are to perform and the priorities;

- detailed planning of concrete applications which are preferred in the performance process.

Planning and performance starts with a technical and economical evaluation of the application, followed by a logistical planning of the performance, recorded in a plan of operation through which the progress of the application is verified.

The plan of operation should be carefully analyzed by the auditor in order to identify the efficient and economical use of the resources, that is, the efficiency of the application.

Activities of operation develop in a chronological order through a cycle that contains the entry of data that are to be processed, the operations of processing, and the outcome. Depending on the characteristics of the application, these phases can succeed without interruption or can take place independently, or in a combined way. For example, some data entry can be followed by only one process, and various processes can lead to one single result. Nevertheless, from the auditor's point of view, it is necessary that all three phases be considered, since each of them has distinct characteristics from the point of view of control, efficiency and efficacy.

The auditor is interested in the aspects of performance referring to operation from the following point of view: and its control;

- the level of operation of equipment

- the sufficient amount of physical equipment; 
- the internal organization of the operational group;

- the criteria used in establishing priorities in tasks, the schedule of the tasks and its observance, including the use of resources;

- the control of data that is to be processed and the control of the appropriate documentation;

- the activities of the processing, including document and result control, exceptions and incidence, as well as solutions that have been adopted. This step includes new processing due to errors or equipment malfunction;

- procedures regarding quality control and the process of transferring the results of the processing to the users;

- procedures of recording, safeguarding and control of programs and magnetic storage archives.

Aspects of performance imply a series of risks that represent objects of interest for the auditor:

- the unauthorized use of the processing media, be that the use for other purposes than that of the entity, or the modification of data with an aim to commit unauthorized actions;

- physical damage caused to equipment, by chance or intentionally, risks that require preventive measures (against fire, copying of programs and archives, etc.) as well as concrete plans in case of emergencies;

- the accidental interruption of processing due to power shortage or equipment damage. Taking measures is important both in the case of computer programs and operational procedures in order to preserve the integrity of the processed information, to recover data and to resume processing;

- the accidental loss of data due to operational errors. Prevention is based on appropriate operational procedures, efficient monitoring, correct identification of archives and programs and a strict custodial system. The efficient solution in the case of data loss requires a plan to save data on magnetic storage devices (tapes, disks, etc.) and a method for recovering lost information;

- the theft or unauthorized use of goods, programs, documents and information, including fraudulent use. Preventive measures correspond to an internal control based on the separation of incompatible functions, corresponding records and procedures that denominate responsibility for custody and specify restrictions for access to media.

Methods that are characteristic of information technology have been implemented in order to limit and control access to equipment and data on magnetic storage devices, like personal access keys for various levels of access and confidentiality of information as well as automatic records about the use of the equipment.

\section{Specific Aspects of Auditing the Information Sector \\ Maintenance of application \\ This activity is significant regarding} the use of means and its aim is to implement the necessary changes for information applications, as a consequence of the modification of circumstances, be those normative (a new contract, etc.) or management decisions (new products, new clients, new plan of accounts, new prices and sales policies).

The efficiency of the application maintenance greatly depends on the quality of the original application model and the sufficient amount of technical documentation.

The most important aspects of control include an adequate identification of costs that allow the evaluation of consequences and procedures in order to authorize, pursue and implement changes in the application.

\section{Fiscal Control}

The extent of costs in the information department and the related 
technological complexity lead to the necessity of a strict fiscal control of the allotted resources.

The budget for the information department should preferably be structured according to:

- clear assignation of responsibility regarding the budget and the management of resources, the principle of the universality of the budget should be applied, with a preference towards including a high number of averages regardless of localization and aim.

- in allocation method of information costs on each task separately or, on departments with the aim to establish the necessary parameters in order to evaluate efficacy and efficiency and mention alternatives.

The Existence of Integrated Systems

The close relationship between information technology and information system efficiency for the whole entity enables the integration of management systems in an increasingly information dependent system. This integration renders applications as part of superior system components, thus, forcing information science planning to occur in systems, even if its performance is subsequently achieved through applications.

The advantage of this integrated system is that it allows the planning of the information support starting with critical factors necessary for the success of a public entity, assuring the global efficiency of resources. This advantage implies difficulty regarding the effective application of system integration, that is, a clear statement regarding the needs of the system, regarding the data it contains and the dependence within this data. In the case of integrated information systems the auditor focuses in the assessment of the sufficient quantity that enables those systems to satisfy needs of negotiation and management.

\section{Internal Control}

Frauds and other irregularities represent a constant danger to efficacy, efficiency and economy in the use of information resources. This is applicable to sectors of the entity that where information technology is integrated with the performance management process. The evaluation of the internal control system is integrated, but from a practical point of view the emphasis is on those components which occur in each operational sector submitted to the assessment.

The general requirements of internal control are applicable in the information system but there exist some details and specific needs that depend on the technical complexity and the value of the information resources.

Such necessities are:

- at the time their system and applications are created, rules of information security and internal control should be observed when information is transferred. This can occasionally cause limitations regarding the flexibility and operationality of the mechanized system, which could be argued for through the advantages they offer through a better control;

- the separation of functions, especially that of incompatible tasks from the point of view of internal control;

- physical security with measures to control unauthorized access to installations, equipment, programs and data. These aspects of security represent the greatest difficulty due to the complexity and rapid changes in information technology and communication;

- the activity of the internal auditing that includes controls for systematic and independent checks of process and data integrity for resources stored on magnetic storage.

The auditor can carry out these controls on his own computer through a special auditing program or programs used in information operation.

Equipment Acquisition

Equipment acquisition is the most 
important factor in the economy of resource management. When, how much and how equipment is purchased relates to problems that require solution through the planning of the use of information technology in global operations.

This activity is normally recorded in a document known as plan of systems or robotism, which is assessed by the auditor from the point of view of coherence, viability, cost and objectives. The evaluation of equipment acquisition economy should take place within the context of robotism, be that first installation, replacement of already existing equipment or the increase of the processing capacity.

The lack of a satisfactory planning or an important deficiency referring to exerting control significantly limits future levels of efficacy and acquired equipment efficiency.

Another important aspect, after the necessity of equipment, is the way the acquisition occurs that allows a range of options between buying and renting, influencing both financial and technical aspects as well as comparative advantages in efficacy and efficiency of new offers that constantly appear on the market of information technology and communication.

\section{Conclusions}

Information system auditing represents the activity of collecting and evaluating data in order to determine if it is safely processed, maintains the integrity of the processed and stored data, allows the security of strategic objectives of the enterprise, and uses information resources efficiently.

In order to establish the nature, duration and the amplitude of auditing activities, the auditor needs sufficient knowledge in information science to accomplish the analysis of the processing procedures and their results.

The auditing of simple information systems that process data by algorithms of calculation easy to be applied, does not impose computer-based testing procedures; in such cases, the auditors compare the results of test data processing, manually obtained, with the results provided by the audited system itself and compare differences; this technique is called auditing by avoiding the computer because auditors avoid computers when the auditing activity is carried out.

The auditing of complex information systems requires the use of auditing procedures on a computer and the planning of supplementary tests in order to control these procedures.

The planning, achievement and use of computer-based auditing techniques require auditors to have, beside their sound knowledge of economy, supplementary knowledge in information science and be informed on the activities of the public institutions to be audited.

\section{References}

[1] Arsac, J. Informatics, Romanian Encyclopedic Publisher, Bucharest, (1973).

[2] Champlain, J., Auditing Information Systems, Second Edition, John Wiley \& Sons Inc., (2003), USA.

[3] Minculete Ghe., Service and support management elements, Bucharest, National Defense University Publishing House „Carol I”, (2005).

[4] Zaharia M., Cârstea C., Sălăgean L., Artificial inteligence and expert systems in assisting economical decisions, Bucharest, Economic Publisher, (2003). 